Tomasz MŁYNARSKI

Uniwersytet Jagielloński

tomasz.mlynarski@uj.edu.pl

\title{
REFORMA SYSTEMU ZABEZPIECZEŃ \\ I WERYFIKACJI MATERIAŁÓW JĄDROWYCH \\ JAKO WARUNEK BEZPIECZEŃSTWA NUKLEARNEGO W XXI W.
}

ABSTRACT The reform of the nuclear safeguards and verification of nuclear materials as a condition of nuclear safety in the 21 Century

The condition of maintaining nuclear safety in the twentieth century is to ensure a global system of nuclear materials safeguards. In practice, this means the need for a global system of verification of compliance with non-proliferation requirements equipped with mechanisms of international control, accounting and physical protection of nuclear materials and facilities, as means of preventing the usage of nuclear dual-use technology for non-peaceful purposes (construction of nuclear weapons or other nuclear explosive devices). The track record of non-proliferation regime discovered the weakness of the nuclear safeguards and verification system, in particular, limits of the IAEA control functions. Maintaining the "Nuclear Peace" can be assured only by a global system of physical protection, accounting, and security of nuclear materials, which means the need to improve the internationally comprehensive system of verification of compliance with non-proliferation. The aim of the article is to present the principles of the international system of nuclear safeguards and the role of the International Atomic Energy Agency in maintaining nuclear peace and nuclear challenges of non-proliferation regime reform. The analysis leads, among others, to the conclusion that the Agency should develop a procedure to standardize the rules, structure, and terminology of reporting non-compliance, promote the internationalization of the fuel cycle while the UN Security Council should react faster in the case of non-compliance detection.

Słowa kluczowe: energia jądrowa, nieproliferacja, MAEA, system zabezpieczeń jądrowych i weryfikacji 
Keywords: nuclear energy, non-proliferation, the IAEA, nuclear safeguards and verification system

W

arunkiem utrzymania bezpieczeństwa nuklearnego w XXI w. jest zapewnienie globalnego systemu zabezpieczenia materiałów jądrowych (m.in. wzbogaconego uranu, plutonu) dla uniemożliwienia ich użycia jako broni jądrowej. W praktyce oznacza to konieczność utworzenia globalnego systemu weryfikacji przestrzegania zasad nieproliferacji wyposażonego w mechanizmy międzynarodowej kontroli, ewidencji i ochrony fizycznej materiałów i obiektów jądrowych jako środka przeciwdziałania wykorzystania jądrowych technologii podwójnego zastosowania (dual use) do celów niepokojowych (budowa broni jądrowej lub innych jądrowych ładunków wybuchowych). System weryfikacji wymaga jednak pogłębienia, tak aby ostrzec na czas przed ryzykiem produkcji materiałów w celach innych niż pokojowe. Celem artykułu jest przybliżenie zasad działania międzynarodowego systemu zabezpieczeń materiałów jądrowych i roli Międzynarodowej Agencji Energii Atomowej (MAEA) w utrzymaniu pokoju jądrowego oraz wyzwań reformy systemu nieproliferacji.

\section{GENEZA POKOJOWEGO WYKORZYSTANIA ENERGII JĄDROWEJ}

Początki energetyki jądrowej sięgają lat 50. i 60. XX w., kiedy rozpoczęto budowę pierwszych komercyjnych reaktorów energetycznych ${ }^{1}$. Zanim jednak do tego doszło, 15 listopada 1945 r. prezydent Stanów Zjednoczonych Harry Truman, premier Wielkiej Brytanii Clement Attlee oraz premier Kanady Mackenzie King podpisali tzw. Deklarację waszyngtońską w sprawie pokojowego wykorzystania energii atomowej, która przewidywała podzielenie się z innymi państwami doświadczeniami i wiedzą w zakresie pokojowego zastosowania energii jądrowej ${ }^{2}$. W celu uniknięcia niekontrolowanej proliferacji technologii jądrowych podwójnego zastosowania (dual use technologies ${ }^{3}$ ) w styczniu 1946 r. w ONZ powołano Komisję Energii Atomowej (UN Atomic Energy Commission), która rozpatrywała tzw. plan Bernarda Barucha, obejmujący postulat międzynarodowej kontroli wykorzystania energii atomowej. Plan Barucha zakładał

1 Pierwszą generację reaktorów stanowiły konstrukcje przejęte z programów wojskowych, szybko zmodernizowane do zastosowań cywilnych (produkcja energii elektrycznej i ciepła). Pierwszą na świecie komercyjną elektrownią jądrową była oddana do użytku w 1956 r. brytyjska jednostka w Calder Hall (50 MWe). W grudniu 1957 r. oddano do użytku elektrownię jądrową w Shippingport w Pensylwanii.

2 Declaration on Atomic Bomb By President Truman and Prime Ministers Attlee and King, Washington, November 15, 1945, Nuclear Files, [online] http://www.nuclearfiles.org/menu/key-issues/nuclear-energy/history/dec-truma-atlee-king_1945-11-15.htm, 27 XI 2016.

3 Technologia jądrowa to technologia tzw. „podwójnego zastosowania” (dual use), czyli taka, która może zostać wykorzystana do celów pokojowych, jak również do wspomagania wytwarzania broni jądrowej lub innych urządzeń do wybuchu jądrowego. 
powołanie niezależnej międzynarodowej instytucji (international atomic development authority), kontrolującej narodowe programy atomowe, w tym kopalnictwo rud uranu, budowę i eksploatację elektrowni jądrowych oraz wszelkich materiałów rozszczepialnych. Wobec sprzeciwu ZSRR nie został on jednak przyjęty przez Radę Bezpieczeństwa ONZ4.

Katalizatorem upowszechnienia energetyki jądrowej na świecie był program „Atom dla Pokoju” („Atoms for Peace”) przedstawiony przez prezydenta Dwighta D. Eisenhowera 8 grudnia 1953 r. w przemówieniu przed Zgromadzeniem Ogólnym ONZ, polegający na otwartym dostępie do technologii atomowych pod warunkiem ich pokojowego wykorzystywania ${ }^{5}$. Prezydent Eisenhower uważal, iż w ramach międzynarodowej współpracy powinny być rozwijane i budowane reaktory jądrowe w celu wytwarzania energii elektrycznej w tych częściach świata, gdzie jej brakuje. Apelowat: Rzady [...] powinny wspólnie już teraz zainicjować przekazywanie ze swoich zapasów uranu materiatów rozszczepialnych międzynarodowej agencji energii atomowej, która mogtaby wziać odpowiedzialność za utratę, przechowywanie i ochronępowierzonych jej rozszczepialnych $i$ innych materiató $w^{6}$. Eisenhower postulował też utworzenie międzynarodowej agencji zajmującej się wykorzystaniem programu cywilnej energetyki jądrowej.

Deklaracja amerykańskiego prezydenta uruchomiła liczne ambitne plany pokojowego wykorzystania energii jądrowej zarówno w samych Stanach Zjednoczonych, jak i w innych państwach świata. W rezultacie w latach 50. i 60. ubieglego stulecia podpisano wiele dwustronnych umów (nuclear cooperation agreeements) dotyczących udostępniania przez Stany Zjednoczone innym krajom materiałów i technologii jądrowych do zastosowań cywilnych, a amerykańskie laboratoria rozpoczęly szkolenia naukowców w technologii przetwarzania paliwa jądrowego ${ }^{7}$. Ważnym wydarzeniem dla rozwoju energetyki jądrowej na świecie były trzy kolejne konferencje organizowane pod egidą ONZ w Genewie na temat pokojowego wykorzystania energii atomowej. Pierwsza z nich miała miejsce w dniach 8-20 sierpnia 1955 r. Na konferencji tej spotkali się po raz pierwszy uczeni - głównie fizycy jądrowi - z całego świata w celu otwartej wymiany myśli (ok. 2700 uczonych z 38 państw).

The Baruch Plan (Presented to the United Nations Atomic Energy Commission, June 14, 1946), Atomic Archive, [online] http://www.atomicarchive.com/Docs/Deterrence/BaruchPlan.shtml, 22 X 2016.

5 D.D. Eisenhower, Atoms for Peace Speech, International Atomic Energy Agency (IAEA), [online] https://www.iaea.org/about/history/atoms-for-peace-speech, 15 V 2015.

6 Tamże.

7 V. Gilinsky, Nuclear Power, Nuclear Weapons - Clarifying the Links, [w:] Moving Beyond Pretense. Nuclear Power and Nonproliferation, red. H. Sokolski, Carlisle Barracks 2014, s. 120. W 1954 r. Kongres Stanów Zjednoczonych zatwierdził Prawo energii atomowej (Atomic Energy Act), zezwalając na współpracę z państwami trzecimi i transfer do nich reaktorów jądrowych. Stany Zjednoczone dostarczyły reaktory badawcze i uran m.in. do Iranu, Pakistanu, Japonii. Niestety zostały one wykorzystane niezgodnie z przeznaczeniem. Amerykańska pomoc cywilno-jądrowa skutkowała nuklearnym programem wojskowym także w RPA. Współpracę w sektorze energetyki jądrowej rozwijał także ZSRR, który pomógł m.in. Kubie i Libii w rozwoju ich programów jądrowych. Chiny kooperowały m.in. z Pakistanem, a Indie nabyły reaktory atomowe z Kanady, zyskując źródło plutonu do broni jądrowej. 
Wraz z rozwojem na świecie programów jądrowych zaistniała potrzeba większej kontroli prowadzenia i rozwijania badań nad praktycznym zastosowaniem energii jądrowej i ograniczenia ryzyka proliferacji do celów innych niż pokojowe. W tym celu ONZ w październiku 1956 r. powołała autonomiczną i wyspecjalizowaną Międzynarodową Agencję Energii Atomowej (MAEA; statut wszedł w życie 29 lipca 1957 r.) $)^{8}$. Celem Agencji stało się upowszechnienie pokojowego zastosowania energii jądrowej, w tym wykorzystania energii do produkcji elektryczności, a równocześnie ustanowienie systemu zabezpieczeń, by kraje nie używały pokojowej pomocy do celów wojskowych.

\section{MAEA I ANTYPROLIFERACYJNE PRAWO MIĘDZYNARODOWE}

MAEA stanowi samodzielną organizację w ramach systemu Narodów Zjednoczonych i międzyrządowe forum współpracy w zakresie pokojowego wykorzystania energii jądrowej. Pierwotnie miała ona pełnić funkcję wyspecjalizowanej organizacji dostawczej m.in. paliwa jądrowego dla państw członkowskich, ale spotkało się to ze sprzeciwem ZSRR. Agencja stała się swego rodzaju centrum współpracy w dziedzinach związanych z bezpiecznym wykorzystaniem energii jądrowej do celów pokojowych. Najwyższym organem MAEA jest Konferencja Generalna (składa się z przedstawicieli wszystkich państw członkowskich) odbywająca raz w roku (we wrześniu) jedną regularną sesję. Konferencja dokonuje przeglądu działalności MAEA i podejmuje decyzje o członkostwie w Agencji, o jej strukturze, planach działania i finansach. Agencją zarządza Rada Gubernatorów (Board of Governors), która składa się z jednego przedstawiciela każdego państwa członkowskiego ${ }^{9}$. Rada odbywa cztery regularne posiedzenia w roku, podejmując bieżące decyzje programowo-finansowe wyznaczające prace Sekretariatu. Dyrektor generalny, wspierany przez Sekretariat, kieruje bieżącą działalnością organizacji.

Agencja pełni funkcje międzyrządowego forum współpracy w zakresie pokojowego wykorzystania energii jądrowej i kontroli wykorzystania technologii jądrowych w czterech głównych obszarach:

- bezpieczeństwa jądrowego (nuclear safety) - obejmuje reagowanie na sytuacje kryzysowe (konwencje o wypadkach jądrowych, w tym o wczesnym powiadamianiu i pomocy w przypadku awarii jądrowej); w tej części mieści się też działalność informacyjna, a także zabezpieczenie i kontrola zakładów;

- zabezpieczenia jądrowego (nuclear security) - obejmujące ochronę fizyczną materiałów jądrowych (konwencje o ochronie fizycznej materiałów jądrowych i obiektów jądrowych i zabezpieczeniach materiałów jądrowych); w tej kategorii mieści się także konwencja o zwalczaniu aktów terroryzmu nuklearnego

Siedziba MAEA mieści się w Wiedniu, ale organizacja utrzymuje też biura w Genewie, Nowym Jorku, Toronto i Tokio.

9 Rada składa się z 35 członków, z których 13 wyznaczanych jest spośród państw o największym pokojowym programie jądrowym, zaś 22 wyłanianych jest w ramach rotacji (dwuletniej) z grup geograficznych. 
i rezolucja RB 1540, a także działania na rzecz bezpieczeństwa obrotu i zabezpieczania przed przemytem;

- system zabezpieczeń jądrowych $i$ weryfikacji (nuclear safeguards and verification) - w tym obszarze mieszczą się m.in. działania Agencji na rzecz nieproliferacji, m.in. kontrole weryfikacyjne, zapewnienie dostaw i umiędzynarodowienie cyklu paliwowego, a także inicjatywy takie jak utworzenie stref bez broni atomowej;

- promowanie pokojowego użycia energii jądrowej - obejmuje współpracę techniczną w zakresie użycia energii jądrowej, a także promocję nauki (szkolenia, konferencje, sympozja) i pokojowych zastosowań technik jądrowych.

Katalog kompetencji i zadań Agencji jest szeroki i oprócz ogólnej kontroli i weryfikacji użytkowania materiałów i instalacji jądrowych obejmuje również ustanawianie standardów bezpieczeństwa instalacji nuklearnych oraz zagospodarowania odpadów radioaktywnych, a także wymianę informacji naukowej i technicznej. W $1968 \mathrm{r}$. w Agencji powołano specjalistyczną służbę - Departament Zabezpieczeń (Departament of Safeguards) - w celu kontroli działań państw korzystających z energii jądrowej i weryfikacji wykorzystania materiałów jądrowych (które mogą posłużyć do budowy jądrowych środków wybuchowych) ${ }^{10}$.

Szczególnym instrumentem regulującym pokojowe wykorzystanie energii nuklearnej i będącym podstawą światowego systemu prawnego mającego zapewnić „jądrowy pokój" stał się Traktat o nieproliferacji broni jądrowej (Treaty on the Non-Proliferation of Nuclear Weapons, NPT), sporządzony w Moskwie i Londynie 1 lipca 1968 r., który wszedł w życie 5 marca 1970 r. (w 1995 r. przedłużono go bezterminowo). Układ NPT dzieli państwa strony na dwie grupy - państwa dysponujące bronią jądrową (nuclear weapon states, NWS) oraz państwa niedysponujące bronią jądrową (non nuclear weapon states, NNWS) ${ }^{11}$. Państwa posiadające broń i technologie jądrowe o wojskowym zastosowaniu zobowiązują się do ich nieprzekazywania komukolwiek bezpośrednio lub pośrednio, do nieokazywania pomocy, niezachęcania i nienakłaniania państw NNWS do jej produkowania lub do uzyskania jej inną drogą. Państwa nieposiadające zobowiązują się do wyrzeczenia się broni jądrowej i nieubiegania o technologie jądrowe, w zamian otrzymując pomoc w celu pokojowego wykorzystania energii i technologii nuklearnych (np. wytwarzania energii elektrycznej czy napędu statków). Układ podkreśla prawo wszystkich stron do rozwoju badań, produkcji i wykorzystania energii jądrowej wyłącznie do celów pokojowych, przy zachowaniu międzynarodowych procedur kontrolnych. Państwa strony NPT, które chcą wykorzystać energetykę jądrową do celów pokojowych, zobowiązują się do zawarcia odpowiednich porozumień obejmujących system środków zabezpieczających, aby nie dopuścić do przekształcenia energii jądrowej przeznaczonej do celów pokojowych w broń jądrową lub inne jądrowe urządzenia wybuchowe.

10 W 2015 r. Departament Zabezpieczeń zatrudniał 883 pracowników i kontrahentów z 96 różnych państw członkowskich.

11 Kryterium podziału jest wyprodukowanie i zdetonowanie broni jądrowej lub innego jądrowego urządzenia wybuchowego przed 1 I 1967 r. KRLD wycofała się z NPT 10 I 2003 r. Poza układem pozostają: Indie, Pakistan, Izrael, Korea Północna i Sudan Południowy. 


\section{SYSTEM ŚRODKÓW ZABEZPIECZAJĄCYCH WOBEC PROGRAMÓW JĄDROWYCH}

MAEA kształtuje bezpieczeństwo jądrowe od lat 70. XX w., kiedy rozpoczęła opracowywanie wytycznych dla ochrony fizycznej materiałów jądrowych ${ }^{12}$. Dokument został opublikowany w czerwcu 1972 r. jako Zalecenia w zakresie ochrony fizycznej materiałów jądrowych (INFCIRC/225 13 - wielokrotnie uaktualniany), które definiują zabezpieczenia reaktorów energetycznych i doświadczalnych (w tym przed kradzieżą wypalonego lub świeżego paliwa).

Z czasem MAEA stała się swego rodzaju „strażnikiem” postanowień NPT, a system zabezpieczeń i weryfikacji - głównym instrumentem utrzymania "pokoju jądrowego". Pierwotne znaczenie terminu „zabezpieczenia” (safeguards) było szerokie i w latach 40. i 50. XX w. używano go w odniesieniu do weryfikacji środków dla zapewnienia rozbrojenia. $\mathrm{Z}$ upływem czasu system zabezpieczeń został zawężony do inspekcji i rozliczania materiałów jądrowych (nuclear accounting), a także innych środków koniecznych, by potwierdzić, że materiał jądrowy stosowany jest do celów pokojowych ${ }^{14}$. Rezultatem systemu safeguards powinno być wydane na czas ostrzeżenie o zmianie zastosowania materiałów jądrowych z celów pokojowych na wojskowe (np. budowa broni) oraz wykrycie potencjalnych niezgodności i odstraszenie przed działaniami wbrew reżimowi NPT. Reżim NPT wprowadził prawny obowiązek dla państw stron NNWS objęcia wszystkich ich działań jądrowych zabezpieczeniami Agencji.

W drugiej połowie lat 70. ubiegłego wieku zainicjowano też działania odnośnie do międzynarodowego zarządzania wszystkimi aspektami jądrowego cyklu paliwowego. Inicjatywa została zapoczątkowana w 1977 r. przez prezydenta Jimmy’ego Cartera, który dążył do ustanowienia oceny cyklu paliwowego (International Nuclear Fuel Cycle Evaluation, INFCE), czyli „odpornych na proliferację” porozumień, które miały przywrócić zaufanie, że cywilne użycie energii jądrowej nie będzie wspierać programów wojskowych ${ }^{15}$.

12 T. Findlay, The Role of the IAEA in Nuclear Security Diplomacy After 2016, Belfer Center for Science and International Affairs/Harvard Kennedy School, III 2014, s. 12.

13 IAEA, Nuclear Security Recommendations on Physical Protection of Nuclear Material and Nuclear Facilities (INFCIRC/225/Revision 5), Vienna 2011, IAEA Nuclear Security Series, 13, [online] http:// www-pub.iaea.org/MTCD/publications/PDF/Pub1481_web.pdf, 22 X 2016.

14 Zabezpieczenia to działania na szczeblu globalnym, regionalnym i krajowym, przewidziane traktatem NPT w celu skutecznego zabezpieczenia materiałów jądrowych w kontekście efektywnego zapobieżenia rozprzestrzenianiu się broni jądrowych.

15 Grupy robocze INFCE przeprowadziły łącznie w latach 1977-1979 134 spotkania w Wiedniu z udziałem przedstawicieli 66 państw, za: R. Skjoldebrand, The International Nuclear Fuel Cycle Evaluation INFCE, „IAEA Bulletin” 1980, Vol. 22, nr 2, s. 31. W latach 80. XX w. państwa, które posiadały największe rezerwy plutonu (Belgia, Niemcy, Włochy i Szwajcaria), podjęły samodzielne wysiłki, w efekcie których Agencja w 1998 r. przyjęła wytyczne dla zarządzania plutonem (Guidelines for the Management of Plutonium; INFCIRC/549). 
Wraz z utworzeniem NPT oraz zgodnie ze statutem (art. III.5) Agencja podjęła się weryfikacji zgodności aktywności jądrowej krajów NNWS z ich zobowiązaniami wynikającymi z nieproliferacji, poprzez prawo ustalania i stosowania środków zabezpieczaja$c y c b^{16}$. Państwa strony układu poddały się kontroli MAEA przestrzegania postanowień układu dla zapewnienia, że programy jądrowe realizowane w tych państwach mają rzeczywiście charakter pokojowy. Weryfikacja następuje na mocy porozumień o środkach zabezpieczających (safeguards agreements) przewidzianych w traktacie o nieproliferacji broni jądrowej NPT. Celem systemu zabezpieczeń jest sprawdzenie, czy deklarowana działalność lub materiały nie są wykorzystywane do wytwarzania broni jądrowej. Agencja administruje zatem systemem zabezpieczeń obejmującym weryfikację wykorzystania materiałów rozszczepialnych (pluton, wysoko wzbogacony uran). Elementem weryfikacji w ramach „środków zabezpieczających” są inspekcje (art. XII Statutu) ${ }^{17}$, które stuża potwierdzeniu, że pokojowe programy jądrowe nie sa wykorzystywane w innych celach niż pokojowe. MAEA uzyskała uprawnienie kontroli obiektów i działalności związanej z materiałami rozszczepialnymi, ale tylko za zgodą i w odniesieniu do wskazanych przez państwo obiektów ${ }^{18}$. Przeprowadzane są one na podstawie procedury o zabezpieczeniach wszechstronnych (MAEA INFCIRIC/153), tzn. każde państwo niedysponujące bronią jądrową (NNWS) będące stroną układu NPT jest zobligowane (indywidualnie) zawrzeć z Agencją dwustronną umowę kompleksowych zabezpieczeń (Comprehensive Safeguards Agreements, CSA), podporządkowującą środkom zabezpieczającym MAEA wszystkie materiaty jądrowe będące w jego posiadaniu ${ }^{19}$. Umowa zawierana między MAEA i państwem stroną NPT o zabezpieczeniach wszechstronnych obejmuje pełną kontrolę działalności państwa w zakresie energii jądrowej, w tym materiałów rozszczepialnych, tak aby nie zostały one przesunięte z zastosowań pokojowych do wytwarzania broni jądrowej. Państwa strony NPT prowadzące działalność jądrową w bardzo ograniczonym zakresie uzupełniły swoje umowy tzw. protokołami małych ilości (small quantitis protocol, SQP), znacznie upraszczającymi procedury przewidziane w CSA. SQP wyłącza większość zobowiązań umowy kompleksowej, takie jak

16 System środków zabezpieczających obejmuje nie tylko reaktory, ale także zakłady przerobu rudy uranu i produkcji paliwa reaktorowego. W połowie 2016 r. 182 państwa podpisały z MAEA umowy o środkach zabezpieczających (safeguard agreements), w tym 174 typu rozszerzonego CSA, pięć VOAs, zaś protokołami dodatkowymi związanych było $128 \mathrm{z}$ nich. Zob. IAEA, IAEA Safeguards Delivering Effective Nuclear Verification for World Peace, [online] https://www.iaea.org/sites/default/files/16/08/ iaea_safeguards_introductory_leaflet.pdf, 20 XI 2016.

17 IAEA, The Statute of the IAEA, [online] https://www.iaea.org/about/statute\#a1-3, 10 X 2016.

18 Kontrola obrotu wzbogaconym uranem oraz technologiami niezbędnymi do jego uzyskania w celach zapewnienia bezpieczeństwa jego produkcji, użytkowania, przetwarzania oraz rozpowszechniania.

19 Państwa członkowskie MAEA mogą zawierać z Agencją także inne specyficzne rodzaje umów o zabezpieczeniach: 1) ograniczonych (IAEA INFCIRC/66), obejmujące kontrolą tylko materiały jądrowe lub działania w zakresie energii jądrowej wyszczególnione w umowie państwa z MAEA; 2) dobrowolnych (Voluntary Offer Agreements, VOAs), przewidujące wycofanie spod kontroli zgłoszonych materiałów lub obiektów z wyłączeniem kontroli działań, które mogą prowadzić do proliferacji materiałów jądrowych (np. w transporcie), za: IAEA, Safeguards Agreements, [online] https://www.iaea.org/safeguards/safeguards-legal-framework/safeguards-agreements, 10 XI 2016. 
deklarowanie i inspekcje, pod warunkiem że działalność jądrowa jest prowadzona tylko w pewnej małej skali ${ }^{20}$.

Ponadto Agencja ma prawo przeprowadzenia specjalnej inspekcji, jeśli inspektorzy podejrzewają istnienie niezadeklarowanych działań lub zakładów. W teorii nie ma ograniczeń prawa dostępu Agencji do prowadzenia takiej inspekcji, w praktyce jednak potrzebna jest zgoda kraju, którego dotyczy inspekcja. Jeśli kraj odmawia, wówczas Rada Gubernatorów może mu nakazać, by zezwolił na dostęp do wskazanych instalacji. Rada Gubernatorów MAEA może wezwać do usunięcia nieprawidłowości oraz zgłosić takie przypadki Radzie Bezpieczeństwa i Zgromadzeniu Ogólnemu ONZ21. W sytuacji jeśli państwo nadal odmawia, Agencja raportuje do RB ONZ, że nie była w stanie zweryfikować, czy nie doszło do wykorzystania materiałów pokojowych do celów wojskowych. W 2010 r. zabezpieczeniami objętych było 175 krajów (i Taiwan) w 949 zakładach, gdzie przeprowadzono 2122 inspekcje na miejscu (w 2015 r. było to już 1286 obiektów i zakładów jądrowych i 2805 inspekcji w terenie) $)^{22}$.

W ramach zawartych umów o zabezpieczeniach państwa udzielają informacji o działalności badawczo-rozwojowej dotyczącej jądrowego cyklu paliwowego, działalności eksploatacyjnej instalacji jądrowych, wydobycia rudy, materiałów wyłączonych spod zabezpieczeń (np. do zastosowań niejądrowych), a także informacji o odpadach promieniotwórczych. Zabezpieczenia obejmują $\mathrm{HEU}^{23}$, pluton i uran 233, wszystkie materiały, które mogą być użyte w broni jądrowej, a także naturalny nisko wzbogacony uran, zubożony uran i tor ${ }^{24}$. Weryfikacja jest przeprowadzana poprzez inwentaryzację i rozliczanie zużycia materiałów jądrowych (nuclear accounting), stosowanie inspekcji terenowych i środków technicznych. Użytkownicy instalacji jądrowych są zobowiązani do prowadzenia ewidencji materiałowej (State System of Accounting for and Control of Nuclear Material), przekazywania Agencji niezbędnych informacji w postaci podstawowych opisów technicznych instalacji jądrowych i określonych raportów oraz do umożliwienia przeprowadzania inspekcji na miejscu.

System weryfikacji i zabezpieczeń MAEA uzupełniają krajowe systemy rachunkowości i kontroli (The State System of Accounting for and Control, SSAC), które są formą państwowej kontroli, mającej na celu rozliczanie materiałów jądrowych w danym

20 Kontrowersje wzbudził przypadek Arabii Saudyjskiej, która podpisała SQP, ale jest państwem o znaczących ambicjach wykorzystania energii jądrowej, co rodzi ryzyko braku wystarczającego nadzoru ze strony Agencji. Dlatego zmieniono zasady obowiązywania tej umowy, tak by państwa, które już posiadają zakłady jądrowe lub mają je w fazie planowania, nie mogły współdziałać z Agencją na podstawie tej umowy. Państwa, które zawarły już taką umowę, zostały zaproszone do jej renegocjowania, tak by spełniły warunki wzmocnionej kontroli. Proces ten postępuje jednak powoli, gdyż jest zależny od woli państw.

21 MAEA od 1981 r. składa coroczne raporty zgodności państw z deklaracjami nieproliferacji do RB ONZ.

22 T. Findlay, Unleashing the Nuclear Watchdog. Strengthening and Reform of the IAEA, The Centre for International Governance Innovation, Ontario 2012, s. 6; IAEA, IAEA Safeguards Delivering... High enriched uranium (HEU) - uran wysoko wzbogacony. 
państwie. Każde państwo strona umowy kompleksowej CSA musi ustanowić i utrzymywać krajowy system kontroli. Efektywność systemu zabezpieczeń zależy w dużej mierze od skuteczności tych instytucji, a krajowe i regionalne instytucje kontrolne są głównymi punktami kontaktu między państwem a Agencją.

System kontroli materiałów jądrowych został wzmocniony po przyjęciu Konwencji o ochronie fizycznej materiałów jądrowych ${ }^{25}$ otwartej do podpisu w Wiedniu i w Nowym Jorku 3 września 1980 r. (weszła w życie 8 lutego 1987 r., uzupełniona „poprawką” z 8 maja 2016 r. $)^{26}$, która obok układu NPT stała się podstawą systemu środków zabezpieczeń opartego na weryfikacji, ochronie fizycznej obiektów i materiałów jądrowych oraz ich ewidencjonowaniu (rachunkowości). Konwencja ta określa m.in. kategoryzację materiałów jądrowych, zasady ich transportu oraz środki przeciwdziałania przemytowi i bezprawnemu handlowi materiałami jądrowymi.

W maju 1997 r., w oparciu o procedurę INFCIRC/540, rozszerzono traktat o NPT o tzw. Protokół dodatkowy (Additional Protocol) zapewniający MAEA pełną możliwość niezależnej weryfikacji materiałów jądrowych ${ }^{27}$. Protokół rozszerza obowiązki państwa (które uprzednio zawarło jakikolwiek rodzaj porozumienia o zabezpieczeniach z MAEA) w zakresie deklarowania, raportowania, a także zapewnia niemal nieograniczony dostęp na miejscu do realizowanych działań z całego cyklu paliwowego - od wydobycia do likwidacji odpadów nuklearnych (umożliwiając powiadomienie o inspekcji z 24-godzinnym, a nawet kilkugodzinnym wyprzedzeniem). Protokół wymaga, by państwa raportowały o produkcji i wyposażeniu urządzeń, które w jakikolwiek sposób powiązane są z energetyką jądrową, a także imporcie i eksporcie w tym zakresie, prowadzonych pracach badawczo-rozwojowych związanych z cyklem paliwowym i planach budowy nowych zakładów jądrowych ${ }^{28}$. Protokół dodatkowy umożliwia Agencji uzyskanie całkowitego obrazu działań państwa w zakresie energetyki jądrowej, w przeciwieństwie do poprzedniego systemu, który opierał się głównie tylko na danych ewidencyjnych dotyczących materiałów i zakładów jądrowych. Umowa Protokołu dodatkowego nie jest odrębnym traktatem ani nie jest protokołem do NPT, ale modelem opartym na indywidualnych negocjacjach dla wypracowania jego „dopasowanej” wersji do oczekiwań państwa, które już posiada umowę o zabezpieczeniach (do której

25 IAEA, Convention on Physical Protection of Nuclear Materials, Viena, 26 October 1979; IAEA, Amendment to the Convention on Physical Protection of Nuclear Materials (INFCIRC/274/Rev.1/ Mod.1), 9 May 2016, [online] https://www.iaea.org/sites/default/files/infcirc274r1m1.pdf, 20 X 2016. W lipcu 2005 r. przyjęto poprawki rozszerzające zasady wynikające z konwencji na wszystkie czynności dotyczące materiałów jądrowych, urządzeń i obiektów jądrowych, określając zasady odpowiedzialności państwa i operatora urządzeń za tę ochronę.

26 Poprawka poszerza zakres obowiązywania konwencji m.in. poprzez obowiązek ochrony fizycznej obiektów jądrowych i materiałów jądrowych podczas użytkowania, przechowywania i transportu, wprowadza obowiązek reżimu ochrony fizycznej, obejmujący materiały i obiekty jądrowe będące w zakresie jurysdykcji danego państwa, ustanawia podstawowe zasady ochrony fizycznej, poszerza katalog czynów zagrożonych karą i definiuje nowe przestępstwa.

27 Model Protocol Additional to the Agreement(s) between State(s) and the International Atomic Energy Agency for the Application of Safeguards, INFCIRC/540.

28 T. Findlay, Uleashing..., s. 62. 
to Protokół dodatkowy jest załącznikiem). Każda umowa Protokołu dodatkowego jest zatwierdzana przez Radę Gubernatorów oraz jest podpisywana i ratyfikowana przez państwo. Największą słabością Protokołu dodatkowego jest to, że jest on dobrowolny, tzn. przyjmują go zazwyczaj te państwa, które zamierzają być w zgodzie z jego wymaganiami. Niektórzy dostawcy technologii jądrowych wezwali, by był to „złoty” (minimalny) standard bezpieczeństwa w wykorzystaniu materiałaów jądrowych i obrocie nimi. Na przykład Australia jest jedynym z krajów kładących nacisk na wdrożenie tego protokołu jako warunku dostaw uranu. Agencja podjęła znaczne wysiłki w celu promowania przystąpienia do protokołu, tak by był on warunkiem koniecznym dla nuklearnego eksportu, co zaakceptowała NSG (Nuclear Suppliers Group) wobec sprzętu, który widnieje na jej listach kontrolnych.

Rozwiązaniem rewolucyjnym byłoby zapewnienie, by przepisy Protokołu dodatkowego były obowiązujące obligatoryjnie. Niestety wśród członków Agencji silny jest sprzeciw krajów niemających intencji jego przyjęcia w sposób dobrowolny. Najbardziej radykalnymi przeciwnikami systemu zabezpieczeń były takie kraje, jak Kuba, Egipt, Indie, Iran, Pakistan, Syria, Wenezuela, które starały się zablokować jego usprawnienia (niektóre z tych krajów miały ambicje rozwoju broni jądrowej). Ponadto kilka państw podejmujących istotne działania w zakresie przemysłu jądrowego nie jest zainteresowanych wdrożeniem tego protokołu (Argentyna, Brazylia, Egipt, Iran i Korea Północna $)^{29}$. Przeciwnicy systemu zabezpieczeń podkreślali, że ingeruje on w poufność komercyjną handlu i bezpieczeństwo (suwerenność) państwa.

\section{PROBLEM NIESKUTECZNOŚCI SYSTEMU ZABEZPIECZEŃ I WERYFIKACJI MAEA}

MAEA, chociaż jest wyspecjalizowaną agendą Organizacji Narodów Zjednoczonych na rzecz bezpiecznego i pokojowego wykorzystania energii jądrowej, nie posiada nieskrępowanych uprawnień dokonywania inspekcji kontrolnych w dowolnym czasie, dowolnej instalacji bez uprzedzenia (nawet jeśli działa na podstawie zawartego tzw. Protokołu dodatkowego do całościowego systemu zabezpieczeń MAEA), wobec czego kraj zobowiązujący się do nieprzetwarzania lub niewzbogacania paliwa nie może być skutecznie zweryfikowany, jeśli nie wykazuje woli współpracy. Częściowa (wyrywkowa) weryfikacja w państwach nie jest nigdy w stu procentach efektywna, stąd trudności $\mathrm{z}$ wykryciem modyfikacji procesu produkcyjnego prowadzących do zastosowań militarnych. Czynniki świadczące o tym, iż w kraju może być prowadzony wojskowy program nuklearny, są następujące ${ }^{30}$ :

- kraj zaprzecza lub w sposób nieuzasadniony opóźnia dostęp inspektorom MAEA do instalacji/obiektów jądrowych i/lub nie w pełni współpracuje z Agencją,

29 Tamże, s. 63.

30 T. Młynarski, Energetyka jądrowa wobec globalnych wyzwań bezpieczeństwa energetycznego i reżimu nieproliferacji w erze zmian klimatu, Kraków 2016, s. 222. 
- w kraju jest prowadzone wzbogacanie lub przetwarzanie paliwa, a kraj nie podpisał Protokołu dodatkowego z MAEA,

- państwo gromadzi zapasy uranu U-235 wzbogaconego powyżej 5\%,

- wojskowy establishment jest bezpośrednio lub pośrednio zaangażowany w rozwój pokojowego programu energetyki jądrowej, w tym uczestniczy w procesie zakupów i zamówień publicznych,

- w kraju już wcześniej stwierdzono złamanie naruszeń i zobowiązań NPT,

- kraj rozwijał program broni jądrowej w przeszłości,

- kraj publicznie zagrozil, że wycofa się z NPT,

- istnieją poważne przesłanki, że państwo nabywa nienuklearne komponenty nuklearnych urządzeń (sprzęt podwójnego zastosowania),

- istnieją dowody na to, że krajowi naukowcy podejmują badania nad wybuchami jądrowymi.

Do rozwoju systemu zabezpieczeń znacząco przyczyniły się porażki Agencji w zakresie weryfikacji zgodności państw z NPT. MAEA nie wykryła znaczących niezgodności w programach jądrowych Indii, Iraku, Iranu i Libii objętych programem zabezpieczeń (safeguard agreements) i NPT. Próbna eksplozja indyjskiej głowicy jądrowej 18 maja 1974 r. w podziemnym teście o kryptonimie „Uśmiechnięty Budda” wykazała lukę w systemie zabezpieczeń i doprowadziła do przyjęcia umowy o zabezpieczeniach (INFCIRC/66), stwierdzającej, że żadne przedmioty objęte systemem zabezpieczeń nie mogą być użyte do budowy broni lub innych celów wojskowych bądź do wytworzenia jakiegokolwiek nuklearnego urządzenia wybuchowego ${ }^{31}$.

Odkrycie programu budowy broni jądrowej w Iraku było kolejnym szokiem, gdyż tajne działania miały miejsce równolegle z programem pokojowym, podlegającym weryfikacji Agencji. Nie zdołano wykryć nielegalnych działań prowadzonych na polecenie irackich władz tuż obok miejsc, gdzie miały miejsce regularne wizyty inspektorów Agencji. W konsekwencji MAEA była postrzegana jako nieskuteczna, aczkolwiek wynikało to z ograniczenia systemu inspekcji, którego zasady zostały zaprojektowane głównie dla otwartych na współpracę, zaawansowanych krajów przemysłowych. System zabezpieczeń był zbyt słaby, by wykryć tajne instalacje w zamkniętym społeczeństwie. Głównym źródłem niepowodzeń Agencji było to, że inspektorzy skupiali się wyłącznie na zadeklarowanych materiałach jądrowych i zakładach, a narzędziem wykrycia niezgodności była inwentaryzacja i ich rozliczanie.

Po udziale w zniszczeniu nielegalnej irackiej infrastruktury jądrowej zgodnie z zaleceniami Rady Bezpieczeństwa ONZ MAEA odzyskała wiarygodność w oczach wielu krytyków. RB ONZ zobowiązała władze Iraku do współpracy i umożliwienia dostępu inspektorom Agencji o każdym czasie i w każdym miejscu do podejrzanych instalacji i materiałów. Agencja nabyła dzięki temu nowe doświadczenia w prowadzeniu postępowań weryfikacyjnych ${ }^{32}$.

31 T. Findlay, Uleashing..., s. 59.

32 Tamże, s. 60. 
Po porażce kontroli irackiego programu jądrowego w latach 90. XX w. Agencja podjęła bardziej aktywne działania na rzecz poszerzenia czynności weryfikacyjnych, obejmujące wykrycie niezadeklarowanych materiałów i zakładów jądrowych, nielegalne transfery nuklearne, przemyt i działania prowadzące do budowy broni jądrowej. Wzmocnienie systemu zabezpieczeń w latach 1991-2005 nastąpiło poprzez wprowadzenie:

- wymiany informacji o budowie obiektów jądrowych (design information) oraz możliwość dobrowolnego zgłoszenia obiektów do kontroli (voluntary measures),

- możliwość pobierania próbek środowiskowych z dowolnych miejsc wybranych przez MAEA,

- zdalnego monitoringu (system obserwacyjno-rejestrujący) pracującego w sposób ciągly,

- nowego rodzaju inspekcji, tzw. „nieplanowanych”, zapowiadanych w czasie trwania inspekcji rutynowej,

- analizy informacji pochodzących z różnych źródeł (prasa, publikacje naukowe, patenty, zdjęcia satelitarne itp.), w tym dotyczących cyklu paliwowego (od wydobycia rud uranowych do przerobu odpadów) i obiektów związanych z techniką jądrową.

Kolejnym sukcesem Agencji było odkrycie w 1992 r. w Korei Północnej niezgodności z nową umową o zabezpieczeniach. Agencja wykryła je jako pierwsza po sprawdzeniu, że północnokoreańskie deklaracje ilościowe odnośnie do produkcji plutonu były nieprawdopodobnie niskie. Agencja z powodzeniem dokonała także weryfikacji zamknięcia jądrowego programu wojskowego przez RPA w $1993 \mathrm{r}^{33}$

Agencji nie udało się natomiast - przez ponad dwie dekady - wykryć nielegalnych działań Iranu, co zostało ujawnione przez Stany Zjednoczone i Wielką Brytanię w grudniu 2003 r. Agencja zbadała dowody militaryzacji i powiązania między irańskim programem wojskowym a podawanym za pokojowy programem nuklearnym. Lista niezgodności sięgała od laboratoryjnych eksperymentów na plutonie i HEU, przez budowę niezadeklarowanych zakładów jądrowych, aż do badań projektów broni jądrowej oraz testowania składników związanych z uzbrojeniem jądrowym. Raport z listopada 2011 r. na temat Iranu zawierał najwięcej szczegółów dotyczących domniemanej militaryzacji technologii jądrowych spośród wszystkich, jakie Agencja kiedykolwiek przygotowała $^{34}$. Po odkryciu, że Iran był blisko budowy broni jądrowej, Agencja w dniu 18 grudnia 2013 r. podpisała z nim Protokół dodatkowy (nuclear safeguard) celem wzmocnienia systemu weryfikacji (opóźniając jednak jego wejście w życie) ${ }^{35}$.

33 W latach 90. XX w. w zmienionej sytuacji politycznej (koniec zimnej wojny oraz perspektywa rychłego upadku apartheidu) RPA samodzielnie zdecydowała o rezygnacji z posiadania broni jądrowej i zwróciła się do MAEA, by ta zweryfikowała zakończenie programu. W $1991 \mathrm{r}$. kraj ten przystąpił do NPT oraz zawarł porozumienie o środkach zabezpieczających z MAEA. Weryfikacja MAEA wykazała, że w latach 1979-1989 RPA zbudowała, a następnie zdemontowała (do połowy 1991 r.) broń jądrową, za: T. Młynarski, Energetyka jądrowa..., s. 236-237.

34 IAEA, Implementation of the NPT Safeguards Agreement and Relevant Provisions of Security Council Resolutions in the Islamic Republic of Iran, Director General, GOV/2011/65, 8 November 2011, [online] https://www.iaea.org/sites/default/files/gov2011-65.pdf, 15 XI 2016.

35 IAEA, Iran Signs Additional Protocol on Nuclear Safeguards, [online] https://www.iaea.org/newscenter/news/iran-signs-additional-protocol-nuclear-safeguards, 15 XI 2016. Do października 2016 r. po- 
Po identyfikacji niezadeklarowanej działalności jądrowej Agencja otworzyła się na nowe sposoby gromadzenia informacji, m.in. wykorzystując informacje wywiadowcze krajów członkowskich. Ponadto inspektorzy śledczy Agencji działają bardziej niezależnie i nie skupiają się tylko na mechanicznym przeliczaniu materiałów jądrowych, lecz z większą swobodą decydują o sposobie kontroli, tak by jej cel został osiągnięty (uwzględniając wyniki poprzednich inspekcji).

\section{REFORMA MAEA NA RZECZ USPRAWNIENIA SYSTEMU KONTROLI PROGRAMÓW JĄDROWYCH}

System zabezpieczeń jądrowych (nuclear safguards) został znacząco wzmocniony w ostatnich latach, niemniej jednak wzrost liczby reaktorów badawczych i energetycznych na świecie rodzi potrzebę usprawnień i udoskonalenia mechanizmów kontroli programów jądrowych, szczególnie w zakresie wykrywania niezadeklarowanych materiałów, zakładów i działan ${ }^{36}$. Agencja jest silnie ograniczona przez preferencje krajów członkowskich i nie ma uprawnień policyjnych do weryfikacji państwa podejrzanego o działania nielegalne ${ }^{37}$. Problematyczne jest także postępowanie w przypadku wycofania się kraju z NPT, a w konsekwencji z porozumienia o zabezpieczeniach. Państwo strona może bowiem w sposób zupełnie legalny po notyfikacji (trzymiesięczny okres wypowiedzenia) opuścić traktat (art. X NPT). Słabością systemu zabezpieczeń jest to, że nie może on ocenić lub wykryć prawdziwych intencji państwa (ewentualnych planów militaryzacji materiałów jądrowych). Dodatkowymi zewnętrznymi czynnikami ryzyka systemu zabezpieczeń są upowszechnienie cywilnej energetyki jądrowej i globalizacja handlu jądrowego, a także „podziały polityczne” w Agencji (Rada Gubernatorów i Dyrektor Generalny są ciałami politycznymi ${ }^{38}$.

Agencja potrzebuje zatem reformy obejmującej poszerzenie jej kompetencji kontrolnych. Agencja nie jest jednostką wywiadowczą dążącą do zdobycia tajnych informacji o działalności jądrowej państw członkowskich i opiera się na informacjach otrzymanych dobrowolnie od państw członkowskich. Ponadto niezbędne jest bardziej precyzyjne zdefiniowanie, czym jest „niezgodność”. Czy obejmuje ona wszystkie naruszenia umowy o zabezpieczeniach, nawet te niewielkie? Czy brak współpracy z MAEA sam w sobie stanowi niezgodność? (jak to miało miejsce w przypadku Korei Północnej). Rada powinna przyjąć jasne stanowisko, że obowiązkiem każdego państwa

rozumienie nie weszło w życie, za: IAEA, Status of the Additional Protocol, [online] https://www. iaea.org/safeguards/safeguards-legal-framework/additional-protocol/status-of-additional-protocol, 15 XI 2016.

36 Wzrost zużycia energii elektrycznej w krajach rozwijających się sprawia, iż wiele z nich planuje budowę lub już buduje elektrownie jądrowe. Są to m.in.: Algieria, Turcja, Jordania, Arabia Saudyjska, Zjednoczone Emiraty Arabskie, Egipt, Indonezja, Wietnam, Tajlandia, Polska, Argentyna, Brazylia, RPA, Sudan.

37 T. Findlay, Uleashing..., s. 7.

38 Tamże, s. 67. 
członkowskiego MAEA jest udowodnić brak niezgodności wobec Agencji, a nie odwrotnie. Agencja powinna także rozważyć wdrożenie następujących zasad dla wzmocnienia reżimu NPT ${ }^{39}$ :

- wycofanie się z NPT powinno być niemożliwe - poprzez np. stworzenie odpowiednich obwarowań prawnych, a umowy o zabezpieczeniach powinny być bezterminowe,

- w przypadku wycofania się z NPT kraj nie powinien mieć prawa używania materiałów jądrowych, wyposażenia, sprzętu i technologii, które otrzymał, i powinien je zwrócić, a RB ONZ zgodnie z rozdziałem VII Karty NZ powinna działać automatycznie w oparciu o mapę drogową w celu zapewnienia większej skuteczności sankcji wobec kraju naruszającego reguły NPT,

- ograniczenie dostępu krajów członkowskich NPT do produkcji materiałów używanych do konstrukcji broni jądrowej (restrykcje technologiczne i umiędzynarodowienie cyklu paliwowego),

- rozszerzenie nadzoru i kompetencji kontrolnych inspekcji MAEA,

- włączenie krajów spoza układu w reżim NPT (Indie, Izrael, Pakistan, Korea Północna).

Należy udoskonalić techniki inspekcji. Obecny system zabezpieczeń nie zawsze jest w stanie dostarczyć na czas ostrzeżenia o nielegalnym przekształceniu materiału rozszczepialnego. Inspektorzy Agencji powinni mieć zapewniony nieskrępowany dostęp do wszystkich etapów cyklu paliwowego, począwszy od wydobycia uranu, do zakładów przetwarzania odpadów nuklearnych we wszystkich lokalizacjach, tzn. wszędzie tam, gdzie materiał jądrowy jest obecny, a nie w miejscach wskazanych na mocy dodatkowych porozumień o zabezpieczeniach. Pogłębienie systemu weryfikacji obejmowałoby nie tylko proste rozliczanie, ewidencjonowanie i inwentaryzację zużytych materiałów, ale także nieograniczoną weryfikację na miejscu przez międzynarodowy inspektorat. Uprawnienia kontroli reaktorów i zakładów wzbogacania paliwa jądrowego przez MAEA powinny być rozwinięte i obejmować zezwolenie na stałe monitorowanie zakładów jądrowych, by zapewnić, że są one używane wyłącznie do celów pokojowych. Istotne byłoby wdrożenie specjalnych rodzajów inspekcji będących kategorią pośrednią między inspekcjami rutynowymi a inspekcjami w przypadkach, w których istnieją nadzwyczajne okoliczności podejrzenia o niezgodność. Agencja powinna także rozszerzyć mandat inspekcji i wdrożyć nowe techniki weryfikacji, szczególnie w celu wykrycia niezadeklarowanych zakładów i materiałów. Wymaga to bliższej współpracy między Agencją a krajowymi i regionalnymi systemami weryfikacji celem rozliczania i kontroli materiałów jądrowych.

Efektywnie funkcjonujący system zabezpieczeń wymaga opracowania i wdrożenia nowych zasad kontroli opartych na podejściu multilateralnym i stworzenia mechanizmów global nuclear safeguard governance, co przede wszystkim wymaga woli politycznej wschodzących potęg jądrowych (emerging nuclear powers). Protokół dodatkowy (INFCIRC/540) powinien być „złotym standardem” systemu zabezpieczeń jądrowych

39 T. Młynarski, Energetyka jądrowa..., s. 234. 
i stać się warunkiem dostaw wszystkich materiałów i technologii jądrowych oraz wymogiem dla wszystkich państw ubiegających się i wdrażających po raz pierwszy energetykę jądrową.

Osobną kwestią jest niedoinwestowanie Agencji, biorąc pod uwagę jej odpowiedzialność i oczekiwania, jakie się jej stawia. Koszty działań weryfikujących Agencji szczególnie wzrosły po wprowadzeniu umów na bazie Protokołu dodatkowego z $1997 \mathrm{r}$. W ciągu ostatnich 25 lat liczba zakładów objętych zabezpieczeniami potroiła się, a ilość wysoko wzbogaconego uranu (HEU) oraz plutonu objętego systemem nadzoru zwiększyła się sześciokrotnie ${ }^{40}$. Stosowanie zabezpieczeń do cywilnych obiektów jądrowych w Indiach (kraju, który nie jest stroną NPT) powoduje poniesienie przez Agencję znacznych dodatkowych kosztów szacowanych w 2014 r. na 2,7 mln euro ${ }^{41}$. W 2007 r. dyrektor generalny MAEA Mohamed El Baradei zawnioskował wzrost o 22\% regularnego budżetu Agencji na lata 2008-2009, krytykując odmowę Rady Gubernatorów zwiększenia budżetu choćby o 4,6\% w 2008 r., i ostrzegł, że funkcja zabezpieczeń (safeguards) jest systematycznie osłabiana ${ }^{42}$. Dlatego wzmocnienie Agencji będzie wymagało dodatkowych zasobów finansowych, które powinny być dostarczone szczególnie przez te państwa, które rozwijają przemysł jądrowy (Brazylia, Chiny, Indie, Korea Południowa).

Istotnym postępem jest rozpoczęcie przez Agencję realizacji jej pierwotnej misji - banku paliwa jądrowego - gwarantującego dostawy paliwa jądrowego dla krajów członkowskich, które zrezygnują z możliwości jego wytwarzania. W czerwcu 2004 r. El Baradei wystąpił z inicjatywą wypracowania zasad wielostronnego podejścia do cyklu paliwowego. Propozycja obejmowała gwarantowane dostawy paliwa oraz uwielostronnienie cyklu paliwowego. We wrześniu $2006 \mathrm{r}$. inicjatywę poparła pozarządowa The Nuclear Threat Initiative, która zaoferowała $50 \mathrm{mln}$ dolarów na rzecz utworzenia zapasów LEU, dostępnych dla państw wywiązujących się ze zobowiązań nieproliferacji. Państwa członkowskie MAEA dostarczyły dodatkowe $100 \mathrm{mln}$ dolarów (były to m.in. Zjednoczone Emiraty Arabskie, Kuwejt, Norwegia, Stany Zjednoczone), dzięki czemu inicjatywa została zaakceptowana przez Agencję w lutym $2010 \mathrm{r}^{43}$ Powołano Zespół ds. Banku Paliwa (Fuel Bank Team) w ramach Departamentu Energii Jądrowej MAEA. W 2006 r. Rosja zaproponowała utworzenie systemu międzynarodowych centrów cyklu paliwowego oferujących paliwo reaktorowe zainteresowanym państwom, bez przenoszenia poufnych technologii, co ograniczyłoby rozwój krajowych programów cyklu paliwowego ${ }^{44}$. Doprowadziło to do ustanowienia stałej rezerwy LEU do-

40 T. Findlay, What Price Nuclear Governance? Funding the International Atomic Energy Agency, Belfer Center for Science and International Affairs/Harvard Kennedy School, III 2016, s. 19.

41 Tamże.

42 Tamże, s. 10-11.

43 Tenże, Uleashing..., s. 77.

44 Inicjatywa została zatwierdzona przez Agencję w listopadzie 2009 r., a w marcu 2010 r. Agencja podpisała porozumienie z Rosją dotyczące ustanowienia gwarantowanej rezerwy LEU (LEU Guaranteed Reserve) w Angarsku (120 ton LEU wzbogacownego do 4,95\%) dla jej państw członkowskich, które samodzielnie ze względów politycznych nie będą w stanie nabyć LEU na wolnym rynku, za: IAEA, 
stępnej dla państw członkowskich MAEA. Ponadto w sierpniu 2015 r. pod auspicjami MAEA powołano pierwszy na świecie bank nisko wzbogaconego uranu (low-enriched uraniom, LEU) w Oskemen w północno-wschodnim Kazachstanie, kraju będącym największym na świecie producentem uranu ${ }^{45}$. Bank LEU MAEA, który ma rozpocząć prace w 2017 r., będzie zarządzany przez Kazachstan, ale pozostanie własnością i znajdzie się pod jurysdykcją MAEA. Kluczową zasadą IAEA LEU Bank (IAEA Low Enriched Uranium) jest zapewnienie dostaw w sytuacji kryzysowej, tzn. gdy kraj członek MAEA, nie mogąc otrzymać paliwa z rynku komercyjnego, może poprosić MAEA o dostawę paliwa z banku ${ }^{46}$. Uran może być wykorzystany wyłącznie jako paliwo do reaktora energetycznego i nie może być bez zgody MAEA przetwarzany lub reeksportowany. Ma to odwieść kraje od budowy zakładów, które mogłyby zostać wykorzystane do wzbogacania uranu do klasy wojskowej. IAEA LEU Bank jest częścią globalnych wysiłków na rzecz nieproliferacji i jako element mechanizmu zabezpieczenia dostaw paliwa wzmacnia odporność jądrowego cyklu paliwowego na nieproliferację broni jądrowej, co jest statutowym zadaniem MAEA.

Agencja zachęca także projektantów reaktorów jądrowych, by rozważali typ zabezpieczeń by design, tj. jeszcze na etapie projektowania ( $\mathrm{w}$ tym zakresie współpracuje m.in. z Kanadą, Finlandią, Szwecją). Agencja angażuje się także w zabezpieczenia repozytoriów geologicznych zużytego paliwa i odpadów jądrowych czy zakładów wzbogacania laserowego. Osobnym obszarem aktywności jest weryfikacja, czy materiał rozszczepialny pochodzący z broni jądrowej i uwolniony z programów obronnych został nieodwracalnie usunięty z zastosowania do celów wojskowych. Jest to szczególnie trudne, gdyż wymaga udostępnienia wrażliwych informacji o materiale jądrowym klasy wojskowej ${ }^{47}$.

\section{WNIOSKI}

- Dotychczasowe funkcjonowanie reżimu nieproliferacji odkryło słabość systemu zabezpieczeń jądrowych i weryfikacji, w szczególności ograniczenia funkcji kontrolnej MAEA wobec przypadków proliferacji. Niezbywalne prawo do pokojowego wykorzystania energii jądrowej (art. IV NPT) niejednokrotnie używane było jako parawan dla rozwoju programów wojskowych (Korea Północna, Irak, Iran, Libia, Syria). Aktualne ramy prawne reżimu nieproliferacji opierają się na dobrowolnej

Assurance of Supply for Nuclear Fuel, [online] https://www.iaea.org/OurWork/ST/NE/NEFW/ Assurance-of-Supply/iuec.html, 15 XI 2016.

45 IAEA and Kazakbstan Agree to Create Nuclear Fuel Bank, World Nuclear News, 27 VIII 2015, [online] http://www.world-nuclear-news.org/UF-IAEA-and-Kazakhstan-agree-to-create-nuclear-fuel-bank-27081501.html, 15 XI 2016.

46 Uran składowany w banku w Kazachstanie będzie wzbogacony maksymalnie do 4,95\% i będzie typowym paliwem do reaktora lekko-wodnego.

47 Obecnie Agencja uczestniczy w projekcie wdrążającym porozumienie z 2000 r. pomiędzy Stanami Zjednoczonymi a Rosją w zakresie zarządzania plutonem (zmienione w 2010 r.). 
współpracy państw członkowskich z inspektorami Agencji. W ciągu najbliższych lat energetyka jądrowa będzie prawdopodobnie rozprzestrzeniać się na nowe kraje. Będzie to wymagać większych środków kontrolnych, nadzorczych i bezpieczeństwa, a w konsekwencji poszerzenia mandatu uprawnień kontrolnych MAEA, tak by skutecznie powstrzymać ryzyko związane z upowszechnieniem cywilnych technologii jądrowych.

- MAEA uzyskała prymat w globalnym zarządzaniu jądrowym (global nuclear governance). System zabezpieczeń wymaga jednak wzmocnienia, tak by Agencja mogła dostarczyć wiarygodnych zapewnień odnośnie do braku niezadeklarowanych działań z wykorzystaniem materiałów jądrowych. Utrzymanie „pokoju jądrowego” może zapewnić tylko globalny system ochrony fizycznej, ewidencji i zabezpieczenia materiałów jądrowych, co oznacza konieczność usprawnienia w skali międzynarodowej powszechnego systemu weryfikacji przestrzegania zasad nieproliferacji. Tak jak ważne jest wykrycie faktu złamania zasad NPT, tak samo ważna jest nieuchronność konsekwencji, jakie powinny spotkać państwo dopuszczające się naruszeń. Dlatego RB ONZ musi być zdolna do szybszej reakcji po tym, gdy złamanie zasad zostanie ujawnione.

- Istotnym ograniczeniem NPT jest brak skutecznych narzędzi (kar i egzekucji) wywierania presji na państwo w przypadku wykrycia przez MAEA nieprawidłowości. $\mathrm{Na}$ forum RB ONZ sankcje często rozbijają się o różne interesy polityczne stałych członków, próbujących chronić kraje sojusznicze (np. Chiny blokowały wiele razy przegłosowanie sankcji wobec Iranu, podobnie Rosja wobec Korei Północnej). Dlatego zalecane byłoby przyjęcie w RB ONZ mechanizmu prawnie wiążących rezolucji, które byłyby automatycznie implementowane w sytuacji wykrycia niezgodności. Wzmocniłoby to legitymizację działań MAEA i uwiarygodniło RB ONZ, zapewniającą wsparcie w sytuacji, gdy kraj naruszający reżim NPT nie jest gotowy do współpracy.

- Agencja powinna wypracować procedurę standaryzacji zasad, struktury i terminologii raportowania niezgodności. Ustanowienie nieograniczonego prawa kontroli MAEA obiektów jądrowych pozwalałoby jasno wskazać kraje naruszające zobowiązania i poddać je sankcjom. Agencja powinna bowiem dostarczyć wiarygodnych gwarancji nie tylko braku przekierowania materiałów jądrowych z zadeklarowanych działań, ale także braku nierejestrowanej działalności. Wprowadzenie takich mechanizmów wymaga głębszej współpracy politycznej państw oraz usprawnienia zasad weryfikacji prawidłowości, poprawności i kompletności deklaracji państwa odnośnie do posiadanych materiałów jądrowych.

- Umiędzynarodowienie cyklu paliwowego w oparciu o wspólne zarządzanie centrami wzbogacania i przetwarzania paliwa jądrowego (banki paliw) przy równoczesnym zwiększeniu roli i kompetencji MAEA wpłynęłoby na wzmocnienie systemu kontroli i weryfikacji. Toteż utworzenie centrów rezerw LEU (Rosja, Kazachstan) jest ważnym krokiem na rzecz multilateralizacji cyklu paliwowego. Rozwój regionalnych ośrodków dostaw i dystrybucji paliwa reaktorowego byłby pożądanym działaniem na rzecz uszczelnienia systemu zabezpieczeń. 


\section{BIBLIOGRAFIA}

The Baruch Plan (Presented to the United Nations Atomic Energy Commission, June 14, 1946), Atomic Archive, [online] http://www.atomicarchive.com/Docs/Deterrence/BaruchPlan. shtml.

Declaration on Atomic Bomb By President Truman and Prime Ministers Attlee and King, Washington, November 15, 1945, Nuclear Files, [online] http://www.nuclearfiles.org/menu/ key-issues/nuclear-energy/history/dec-truma-atlee-king_1945-11-15.htm.

Eisenhower D.D., Atoms for Peace Speech, International Atomic Energy Agency (IAEA), [online] https://www.iaea.org/about/history/atoms-for-peace-speech.

Findlay T., The Role of the IAEA in Nuclear Security Diplomacy After 2016, Belfer Center for Science and International Affairs/Harvard Kennedy School, III 2014.

Findlay T., Unleashing the Nuclear Watchdog. Strengthening and Reform of the IAEA, The Centre for International Governance Innovation, Ontario 2012.

Findlay T., What Price Nuclear Governance? Funding the International Atomic Energy Agen$c y$, Belfer Center for Science and International Affairs/Harvard Kennedy School, III 2016.

Gilinsky V., Nuclear Power, Nuclear Weapons - Clarifying the Links, [w:] Moving Beyond Pretense. Nuclear Power and Nonproliferation, red. H. Sokolski, Carlisle Barracks 2014.

IAEA and Kazakbstan Agree to Create Nuclear Fuel Bank, World Nuclear News, 27 VIII 2015, [online] http://www.world-nuclear-news.org/UF-IAEA-and-Kazakhstan-agree-to-create-nuclear-fuel-bank-27081501.html.

IAEA, Amendment to the Convention on Physical Protection of Nuclear Materials (INFCIRC/ 274/Rev.1/Mod.1), 9 May 2016, [online] https://www.iaea.org/sites/default/files/infcirc274r1m1.pdf.

IAEA, Assurance of Supply for Nuclear Fuel, [online] https://www.iaea.org/OurWork/ST/NE/ NEFW/Assurance-of-Supply/iuec.html.

IAEA, Convention on Physical Protection of Nuclear Materials, Viena, 26 October 1979.

IAEA, IAEA Safeguards Delivering Effective Nuclear Verification for World Peace, [online] https://www.iaea.org/sites/default/files/16/08/iaea_safeguards_introductory_leaflet.pdf.

IAEA, Implementation of the NPT Safeguards Agreement and Relevant Provisions of Security Council Resolutions in the Islamic Republic of Iran, Director General, GOV/2011/65, 8 November 2011, [online] https://www.iaea.org/sites/default/files/gov2011-65.pdf.

IAEA, Iran Signs Additional Protocol on Nuclear Safeguards, [online] https://www.iaea.org/ newscenter/news/iran-signs-additional-protocol-nuclear-safeguards.

IAEA, Nuclear Security Recommendations on Physical Protection of Nuclear Material and Nuclear Facilities (INFCIRC/225/Revision 5), Vienna 2011, IAEA Nuclear Security Series, 13, [online] http://www-pub.iaea.org/MTCD/publications/PDF/Pub1481_web.pdf.

IAEA, Safeguards Agreements, [online] https://www.iaea.org/safeguards/safeguards-legal-frame work/safeguards-agreements.

IAEA, Status of the Additional Protocol, [online] https://www.iaea.org/safeguards/safeguardslegal-framework/additional-protocol/status-of-additional-protocol.

IAEA, The Statute of the IAEA, [online] https://www.iaea.org/about/statute\#al-3. 
Młynarski T., Energetyka jądrowa wobec globalnych wyzwań bezpieczeństwa energetycznego i reżimu nieproliferacji w erze zmian klimatu, Kraków 2016.

Model Protocol Additional to the Agreement(s) between State(s) and the International Atomic Energy Agency for the Application of Safeguards, INFCIRC/540.

Skjoldebrand R., The International Nuclear Fuel Cycle Evaluation INFCE, „IAEA Bulletin” 1980, Vol. 22, nr 2.

Dr hab. Tomasz MŁYNARSKI - adiunkt w Katedrze Stosunków Międzynarodowych i Polityki Zagranicznej INPiSM UJ. Autor monografii, m.in. Bezpieczeństwo energetyczne w pierwszej dekadzie XXI wieku. Mozaika interesów i geostrategii (2011), Francja w procesie uwspólnotowienia bezpieczeństwa energetycznego i polityki klimatycznej Unii Europejskiej (2013), Energetyka jądrowa wobec globalnych wyzwań bezpieczeństwa energetycznego i reżimu nieproliferacji w erze zmian klimatu (2016). 